\title{
Relationships between submicrometer particulate air pollution and air mass history in Beijing, China, 2004-2006
}

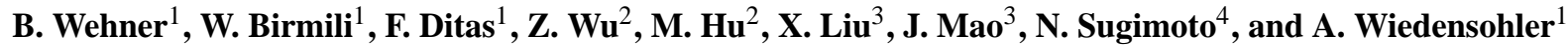 \\ ${ }^{1}$ Leibniz-Institute for Tropospheric Research, 04318 Leipzig, Germany \\ ${ }^{2}$ State Key Joint Laboratory of Environmental Simulation and Pollution Control, College of Environmental Sciences and \\ Engineering, Peking University, Beijing 100871, P. R. China \\ ${ }^{3}$ Department of Atmospheric Sciences, College of Physics, Peking University, Beijing 100871, P. R. China \\ ${ }^{4}$ Atmospheric Environment Division, National Institute for Environmental Studies, Tsukuba, Japan
}

Received: 11 April 2008 - Published in Atmos. Chem. Phys. Discuss.: 10 June 2008

Revised: 5 September 2008 - Accepted: 11 September 2008 - Published: 23 October 2008

\begin{abstract}
The Chinese capital Beijing is one of the global megacities where the effects of rapid economic growth have led to complex air pollution problems that are not well understood. In this study, ambient particle number size distributions in Beijing between 2004 and 2006 are analysed as a function of regional meteorological transport. An essential result is that the particle size distribution in Beijing depends to large extent on the history of the synoptic scale air masses. A first approach based on manual back trajectory classification yielded differences in particulate matter mass concentration by a factor of two between four different air mass categories, including three main wind directions plus the case of stagnant air masses. A back trajectory cluster analysis refined these results, yielding a total of six trajectory clusters. Besides the large scale wind direction, the transportation speed of an air mass was found to play an essential role on the PM concentrations in Beijing. Slow-moving air masses were shown to be associated with an effective accumulation of surface-based anthropogenic emissions due to both, an increased residence time over densely populated land, and their higher degree of vertical stability. For the six back trajectory clusters, differences in $\mathrm{PM}_{1}$ mass concentrations by a factor of 3.5 , in the mean air mass speed by a factor of 6 , and in atmospheric visibility by a factor of 4 were found. The main conclusion is that the air quality in Beijing is not only degraded by anthropogenic aerosol sources from within the megacity, but also by sources across the entire Northwest China plain depending on the meteorological situation.
\end{abstract}

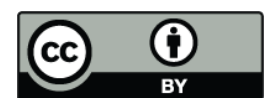

Correspondence to: B. Wehner (birgit@tropos.de)

\section{Introduction}

Beijing with approximately 17 million inhabitants is one of the megacities in the world that are challenged by the imperative necessity of air quality management. Along with the rapid economic growth and increase in motor traffic during the last decade, the characteristics of air pollution in Beijing have changed from typical coal-combustion pollution to a complex mixture of domestic, industrial and traffic emissions combined with the secondary gas and aerosol formation processes in the regional atmosphere. The number of motor vehicles has increased dramatically in Beijing and reached over 3 million in 2007. While the consumption of fossil-fuel energy in China is expected to increase by $50 \%$ until 2020 compared to 1995 (Streets et al., 2001), dust storm events in spring time and re-suspended dust from traffic and construction activities further enhance the complexity especially of particulate air pollution in Beijing. A particular feature of town development in China is that groups of cities grow in parallel and build so-called city clusters. There are four of them these days covering less than $3 \%$ of Chinas territory but $12 \%$ of the total population and producing $47 \%$ of the gross domestic product, GDP (Shao et al., 2006). Beijing belongs to one of these four city clusters making the air pollution situation in combination with its orographic location more delicate and not comparable to other mega cities worldwide (Lawrence et al., 2007). The ongoing economic growth and increasing number of inhabitants and cars without significant reductions in emission rates has lead to an increase in air pollution in the whole area, and will most likely further aggravate this situation in the near future. Morever, the air pollution in Beijing is likely to be affected by emissions from the surrounding areas as well (Guinot et al., 2007).

Published by Copernicus Publications on behalf of the European Geosciences Union. 
The problem of particulate air pollution has become more and more serious during the last decades in terms of visibility degradation as well as an increase in particle-related adverse health symptoms. Beside these local effects, also changes in the regional climate became obvious, such as the decrease of light rain events (Qian et al., 2007b) and a decrease in sunshine duration in China (Kaiser and Qian, 2002). These highly visible observations combined with the fact that Beijing is hosting the Olympic Games 2008 have increased political pressure on the local and state governments to improve the air quality in the very near future. To achieve this, a more comprehensive knowledge of the formation, transformation, and transportation of aerosol particles is required.

A knowledge of the factors controlling high particulate pollution levels is also of great importance for public health, for instance in relation to mortality, and respiratory and cardiovascular diseases. The relationship between particulate air pollution and daily mortality has now been studied for many regions in the world (e.g., Kettunen et al., 2007; Dominici et al., 2005; Analitis et al., 2006). In addition to the mortality studies an increase in hospital admissions and emergency room visits for cardiovascular and respiratory diseases has been recorded at elevated ambient particle concentrations (e.g., Dominici et al., 2006; Kan et al., 2007). Most of the former studies were based on the measurement of particle mass concentration, i.e. TSP, $\mathrm{PM}_{10}$, or $\mathrm{PM}_{2.5}$. During the last decade more studies have targeted $\mathrm{PM}_{2.5}$ (e.g., Schwartz and Naes, 2000; Franklin et al., 2006; Ostro et al., 2006). Based on epidemiologic evidence and results from animal studies on the potential toxicity of ultra-fine particles, recent epidemiologic studies focus on the health effects of particles which are less than $100 \mathrm{~nm}$ in diameter (e.g., Peters et al., 2001, 2007; Ruckerl et al., 2007). The number concentration of these small particles exceeds usually that of larger ones in the urban area, but their contribution to the total mass concentration is relatively low.

Considering number size distributions for epidemiological studies, clearer effects were observed with smaller particle sizes (e.g., Ruckerl et al., 2007; Stölzel et al., 2007; Yue et al., 2007). Until recently, the majority of ambient aerosol measurements in China was limited to aerosol mass concentration and chemical composition (e.g., Wang et al., 2006; Zheng et al., 2005; Huang et al., 2005). Consequently, epidemiological studies have described the effects of mass-related aerosol properties on human health. Qian et al. (2007a) found a consistent evidence of acute effects of $\mathrm{PM}_{10}$ on cardiopulmonary mortality during a four-year study in Wuhan. Kan et al. (2007) found that $\mathrm{PM}_{2.5}$ was associated with death rates from all causes and from cardiorespiratory diseases but not $\mathrm{PM}_{10-2.5}$ in Shanghai. Wong et al. (2002) found a connection between mortality and different pollutants such as $\mathrm{PM}_{10}$ in Hongkong. Particulate air pollution is estimated to be responsible for about one million premature deaths per year in China (Florig et al., 2002). Zhang et al. (2007) pointed out that economic costs to health are up to
$6.5 \%$ of Beijing GDP each year.

Measurements of ambient particle number size distributions down to a few nanometers and aerosol chemical composition would be desirable to help elucidate the health effects of aerosol particles in highly polluted regions like China. Due to statistical reasons as well as the prevalence of longterm effects, such environmental measurements would also be required to be performed over a long period. A number of studies investigating the chemical composition of $\mathrm{PM}_{10}$ or $\mathrm{PM}_{2.5}$ aerosols in Beijing has been performed during the last years (e.g., Wang et al., 2005a; Han et al., 2007; Zheng et al., 2005) but also optical parameters have been measured (e.g., Guinot et al., 2006; Wang et al., 2005b; Xia et al., 2007). The first number-based environmental particle measurements in China were performed with poor size resolution and limited to diameters $>100 \mathrm{~nm}$ ( $\mathrm{Li}$ et al., 2002; Zhong et al., 2003). These authors found general relationships between aerosol number concentration and local meteorology as well as great changes in the characteristics of air pollution in Beijing during the last two decades. Number size distributions down to $6 \mathrm{~nm}$ have been measured by Yu et al. (2005) for one week in summer and two weeks in winter. The analysis of long term number size distribution measurements in the urban area of Beijing, which are useful to analyze trends, give hints about major sources, and to be connected with epidemiological studies have been still missing until 2004. So far, such studies have been performed using models (An et al., 2007) or optical data (Xia et al., 2007).

A joint research measuring site was established by the Leibniz-Institute of Tropos-pheric Research and the Peking University (College of Environmental Sciences and Engineering) in March 2004 to improve the knowledge on the origin of air pollution in the Beijing region. A suite of aerosol measurements was implemented in order to monitor particle number size distributions in the size range $0.003-10 \mu \mathrm{m}$ continuously. Former studies utilising data from these measurements have been published (Wehner et al., 2004; Wu et al., 2007, 2008; Massling et al., 2008). This paper evaluates the size distribution measurements in Beijing over two years, with particular emphasis directed towards the variability in particulate number and volume, their relationship with local sources, air mass history, and further meteorological factors. A major goal is to understand the circumstances causing long-lasting pollution episodes in Beijing and to separate local and regional pollution sources.

\section{Experimental}

\subsection{Measurements site at the Peking University}

Atmospheric measurements were performed on the campus of the Peking University located in the northwest of Beijing, close to the fourth ring road. The sampling site is located on top of a 6-floor building, $20 \mathrm{~m}$ above ground. The location 
is at least $500 \mathrm{~m}$ away from major roads. The campus is a primarily residential and commercial area without industrial sources or agricultural activity. Local emission sources within a radius of $1 \mathrm{~km}$ could be vehicular traffic, fuel combustion for domestic cooking and heating, and construction. An earlier examination of the spatial variability of $\mathrm{PM}_{2.5}$ mass and chemical composition in 1999-2002 showed only minor differences between the campus site and a downtown site. Consequently, the Peking University campus site is assumed as representative for the Beijing environment.

\subsection{Number size distributions}

Aerosol number size distributions are continuously measured between $3 \mathrm{~nm}$ and $10 \mu \mathrm{m}$ since beginning of March 2004. A TDMPS (Twin Differential Mobility Particle Sizer, Birmili et al., 1999) system consisting of two Hauke-type DMAs and two CPCs (model 3010 and model 3025, TSI Inc., St. Paul, MN, USA) is used to measure the size distribution from 3 to $800 \mathrm{~nm}$ (mobility diameter, $D_{p}$ ). Additionally, an APS (Aerodynamic Particle Sizer, model 3321, TSI Inc., St. Paul, MN, USA) measures number size distributions between $800 \mathrm{~nm}$ and $10 \mu \mathrm{m}$ (aerodynamic diameter). Size distributions are taken every $10 \mathrm{~min}$. The data were corrected for losses due to diffusion and sedimentation within the inlet line. To combine both measurements, the APS results were transformed from aerodynamic to Stokes diameters using a particle density of $1.7 \mathrm{~g} \mathrm{~cm}^{-3}$ for the particles larger than $800 \mathrm{~nm}$ as a mean density for the coarse mode. A low flow $\mathrm{PM}_{10}$ inlet is used to minimize contamination by large dust particles. The ambient aerosol is dried in a diffusion drier before entering the air conditioned laboratory to avoid condensation of water in the inlet systems during warm and humid days in summer time. The number size distributions were used to calculate the total number concentration, the submicrometer volume concentration from $3 \mathrm{~nm}$ to $1 \mu \mathrm{m}$ and the total volume concentration from $3 \mathrm{~nm}$ to $10 \mu \mathrm{m}$ assuming spherical particles. Assuming a mean particle density of $1.5 \mathrm{~g} \mathrm{~cm}^{-3}$ the particle mass concentration $<800 \mathrm{~nm}$ (corresponds approximately to $1 \mu \mathrm{m}$ aerodynamic diameter, therefore later called $\left.\mathrm{PM}_{1}\right)$ and $<10 \mu \mathrm{m}\left(\mathrm{PM}_{10}\right)$ was calculated. The assumption of this density is based on previous measurements of chemical particle composition at Beijing. While the coarse mode is dominated by sulfate and crustal material, the submicrometer particles consist mainly of sulfate, organic and elemental carbon (Yao et al., 2003), therefore the densities for submicrometer and supermicrometer particles are assumed to be different. In Beijing, $\mathrm{PM}_{10}$ was found to be dominated by particles $<800 \mathrm{~nm}$, therefore the lower density was used also for the total mass.

\subsection{Meteorological measurements and back trajectories}

Air temperature $(T)$, global radiation $(\mathrm{rad})$, relative humidity $(r H)$, wind speed $(w s)$, and wind direction $(w d)$ were measured at a meteorological station on the University campus $200 \mathrm{~m}$ distant from the aerosol sampling site. A visibility sensor (model FD12, Vaisala, Helsinki, Finland) was operated at the same site. Data from a two-wavelength backscattering lidar (1064 nm and $532 \mathrm{~nm}$ from a Nd-YAG laser) operated by the National Institute for Environmental Studies in Japan have been used to obtain planetary boundary layer depths (PBL) (Sugimoto et al., 2003). Since aerosol concentrations are usually high within the PBL and low above, the PBL depth can be determined from the falling edge of the range-corrected lidar backscattering intensity. The PBL depth is defined here as the height where the normalized gradient of the range-corrected lidar backscattering intensity at $1064 \mathrm{~nm}$ has its minimum. The lidar instrument was located at the Sino-Japan Friendship Center for Environmental Protection in Beijing, around $10 \mathrm{~km}$ east of Peking University.

Regional atmospheric aerosol properties are related to the history of their meteorological air masses. Back trajectories are therefore a useful tool to follow the history of an air mass and to get a better insight into relevant processes and modifications on its way. The back trajectories for Beijing were calculated using the NOAA "On-line Transport and Dispersion Model" (Draxler and Rolph, 2003). The trajectories terminated on a height of $200 \mathrm{~m}$ above ground level. From these data, mean lengths of the back trajectories were computed for periods of 1-3 days representing the mean transportation speed along the trajectory. The longer the trajectory, the higher is the mean transportation speed, because the air mass passed a longer distance within one day. In this study, one trajectory per day has been used, arriving at 12:00 in Beijing. This time was chosen because ground based and elevated air masses are assumed to be well mixed or at least better than at any other of the day because of the boundary layer development.

\section{Results}

\subsection{General overview}

The results shown here generally encompass the Beijing particle size distribution data between March 2004 and March 2006. Before allocating sections of data to specific air masses, daily mean values were calculated for the particle number concentration $N$, particle volume concentration $V$, particle mass concentration PM, an meteorological parameters. Only days with data coverage of at least $22 \mathrm{~h}$ were considered, representing a total of 524 days with available TDMPS and APS measurements. The TDMPS-only data set, which was used to $\mathrm{PM}_{1}$ amounts to a total of 575 days. Excluding the days with desert dust influencing the Beijing air, the supermicrometer aerosol fraction is dominated by anthropogenic emissions and locally re-suspended dust similar to the fraction below $800 \mathrm{~nm}$. The submicrometer and supermicrometer aerosol show a linear relationship with a correlation 

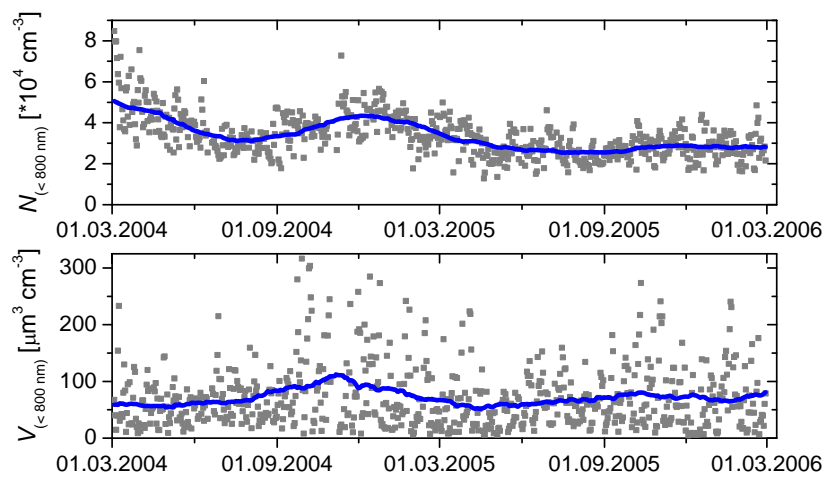

Fig. 1. Daily averages and running mean of calculated particle number $(N)$ and volume $(V)$ concentrations $\left(D_{p}<800 \mathrm{~nm}\right)$ from March 2004 until March 2006.

factor of $0.98\left(\mathrm{PM}_{10}=1.3 * \mathrm{PM}_{1}+14.7\right)$. In the following analysis, we will focus on the particle fraction below $800 \mathrm{~nm}$, because of the larger data availability. Dust days have been generally excluded from the data set. They have been defined by a dominating coarse mode mass faction and log book entry and synchronized with the official list defined by China Meteorological Administration (CMA) described in Yang et al. (2008). During the observed period only 4 days have been classified as dust events.

Figure 1 shows time series of daily averages of number and volume concentrations $\left(D_{p}<800 \mathrm{~nm}\right)$ as well as the running average. In the first half of the data set, a maximum in winter time in both number and volume is recognizable, while the number concentration shows a second maximum during spring 2004. The volume concentration shows a higher variation during winter time. The maximum in number concentration is mainly caused by a high frequency of new particle formation events, which occurs usually in spring, but occasionally also in winter time (Wu et al., 2007). The maximum in volume concentration is due to higher primary emissions in winter time, mainly because of domestic and industrial heating and a lower depth of the mixing layer. If different particle size increments of the number and volume size distributions are considered, then the correlation between the number and volume moments show typical relationships. Quite expectedly, the number of larger particles $\left(D_{p}>100 \mathrm{~nm}\right)$ correlates well with total particle volume because total particle volume is dominated by particles in the accumulation mode. Conversely, an anti-correlation was found for the particle size intervals $<30 \mathrm{~nm}$. The current explanation of this anti-correlation is that high concentration of larger particles (and therefore particle mass) cause smaller particles to collide more frequently and thus reduce their concentration.

A brief statistical analysis of the Beijing measurements yielded averaged number, surface, and volume concentration are $33000 \mathrm{~cm}^{-3}, 1400 \mu \mathrm{m}^{2} \mathrm{~cm}^{-3}$, and $90 \mu \mathrm{m}^{3} \mathrm{~cm}^{-3}$. The number concentration was found to be highest in spring,

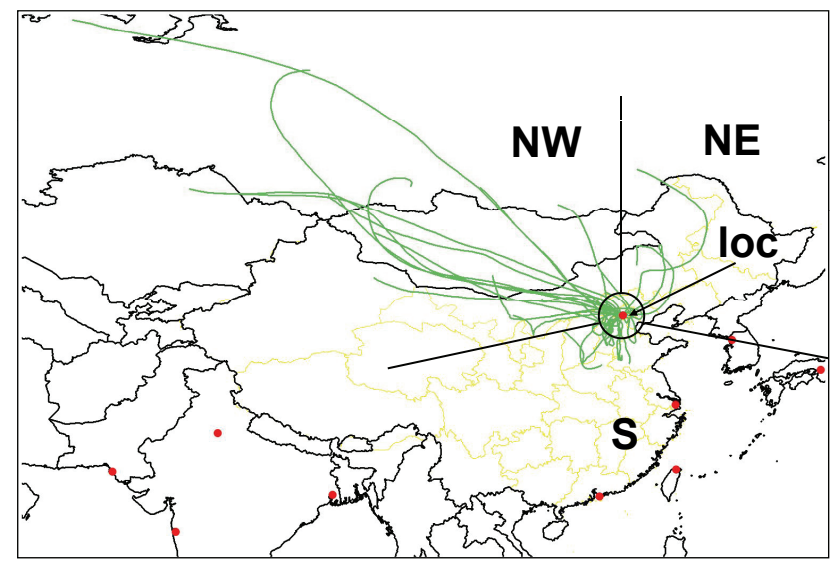

Fig. 2. Representative back trajectories over $72 \mathrm{~h}$ and their classification into four sectors: NW: northwest, NE: northeast, S: south, loc: local Beijing. Red dots mark cities with more than 5 million inhabitants.

while the volume concentration has its maximum during fall. A detailed statistical analysis of the data set is given in $\mathrm{Wu}$ et al. (2008). Average number concentrations in urban areas in Europe or North America were $21000 \mathrm{~cm}^{-3}$ (Atlanta, USA Woo et al., 2001), $22000 \mathrm{~cm}^{-3}$ (Pittsburgh, USA, Stanier et al., 2004), $21000 \mathrm{~cm}^{-3}$ (Leipzig, Germany, Wehner and Wiedensohler, 2003), and $26000 \mathrm{~cm}^{-3}$ (Helsinki, Finland, Ruuskanen et al., 2001) being $60-80 \%$ of the Beijing value. However, the number concentration may also vary significantly within one city (Tuch et al., 2003) and depend strongly on the instrumental size sensitivity; therefore, variations are not unexpected. The volume concentration can be converted to a mass concentration assuming a mean particle density. Taking $1.5 \mathrm{~g} \mathrm{~cm}^{-3}$ as a lower estimate we obtain a $\mathrm{PM}_{10}$ mass concentration of $135 \mu \mathrm{g} \mathrm{m}^{-3}$. $\mathrm{PM}_{10}$ concentrations for European cities have been reported in van Dingenen et al. (2004) with most of the urban and kerbside values were between 40 and $50 \mu \mathrm{g} \mathrm{m}^{-3}$. The highest European value was found at kerbside in Vienna with $55 \mu \mathrm{g} \mathrm{m}^{-3}$. The comparison highlights that particulate mass concentrations in Beijing are currently about a factor of 3 higher than corresponding levels in Europe.

\subsection{Air mass classification}

For the following analysis, measurement days have been classified according to the direction of their 72-h-back trajectories. Four major sectors have been defined: the local one (local) covering the city area of Beijing, and three others of the surrounding regions: northwest (NW), northeast (NE), and south (S), see Fig. 2. However, for some cases the air parcel spent nearly equal times in two of the defined sectors during the $72 \mathrm{~h}$ trajectory. Always, the dominant sector of the trajectory within the last $48 \mathrm{~h}$ has been used for the 


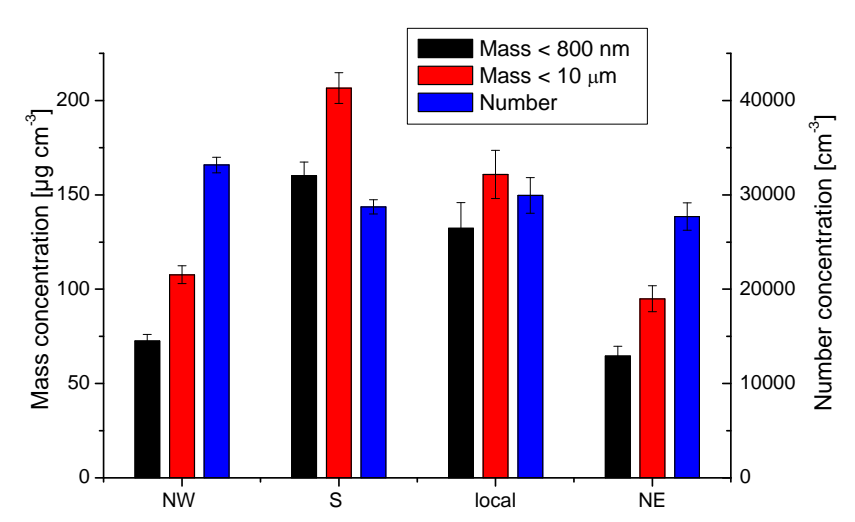

Fig. 3. Mean number and mass concentrations (error bars show standard deviation of the mean values) for the selected back trajectory categories.

classification. Figure 3 shows mean daily mass concentrations $<800 \mathrm{~nm}\left(\mathrm{PM}_{1}\right)$ and $<10 \mu \mathrm{m}\left(\mathrm{PM}_{10}\right)$ as well as number concentrations calculated for each individual day belonging to the main categories of back trajectories according to Fig. 2 . Obviously $\mathrm{PM}_{10}$ and $\mathrm{PM}_{1}$ show a strong dependence on the air mass history: the highest $\mathrm{PM}_{10}$ value of $206 \mu \mathrm{g} \mathrm{m}^{-3}$ was found for air masses coming from the south, the lowest one of $94 \mu \mathrm{g} \mathrm{m}^{-3}$ for air masses from the northeast. The highest concentration in $\mathrm{PM}_{1}$ mass was also found for air masses arriving from the south $\left(160 \mu \mathrm{g} \mathrm{m}^{-3}\right)$, the lowest one again for northeast $\left(64 \mu \mathrm{g} \mathrm{m}^{-3}\right)$. The mean values of total number concentration are between 28000 and $33000 \mathrm{~cm}^{-3}$, while the maximum occurs for air masses from the northwest. The main differences between the air mass types become thus obvious in the mass concentration as a measure for the pollution level. $\mathrm{PM}_{1}$ and $\mathrm{PM}_{10}$ cover different numbers of measurement days because of various interruptions in APS measurements. The ratio between $\mathrm{PM}_{1}$ and $\mathrm{PM}_{10}$ varied between 0.67 for air masses from NW and 0.82 for local air masses. The differences in aerosol characteristics are more obvious in the submicrometer size range in connection with the more complete data set in this range. Therefore, in the scope of this study, the usage of one of them is sufficient. In fact the accumulation mode contributes most to particle volume since dust storm events were excluded from the data set.

Figure 4 shows three more parameters with significant differences for each back trajectory type. The mean boundary layer depth during daytime has been received for most of the measurement days from the two-wavelength backscattering lidar as described above. The mean boundary layer is highest for cases with air mass from the northwest with $1230 \mathrm{~m}$ and lowest for those from the south with $830 \mathrm{~m}$. The mean visibility is highest for the clean air coming from the northwest $(14.3 \mathrm{~km})$ and lowest for those from southern directions $(3.8 \mathrm{~km})$. The visibility is a direct indicator for air quality in the urban area although it is depending on the rel-

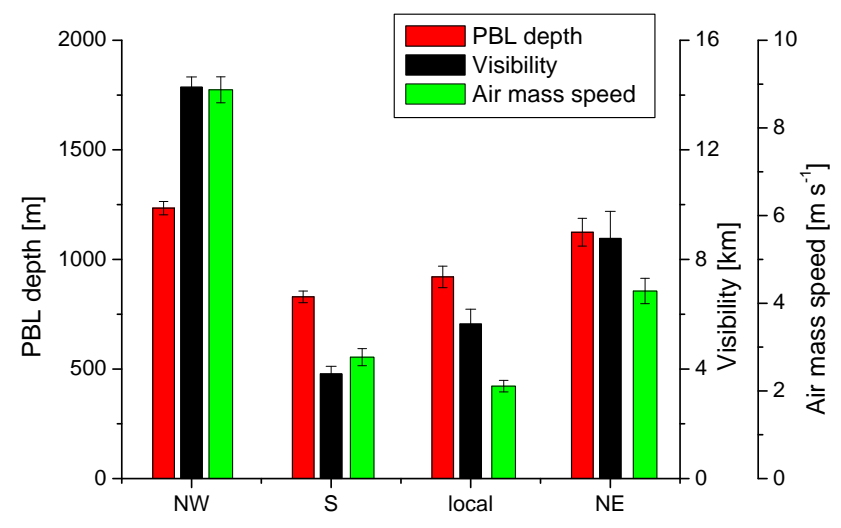

Fig. 4. Mean boundary layer depth (PBL), visibility, and air mass speed for the selected back trajectory categories.

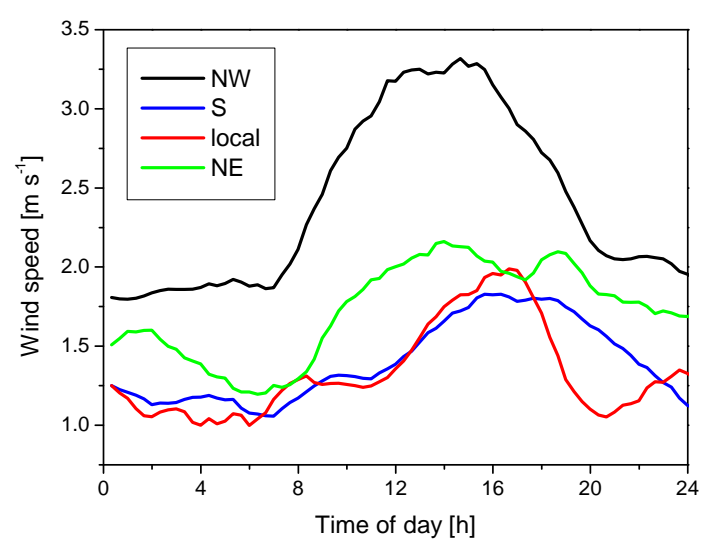

Fig. 5. Mean diurnal variation of wind speed for the selected back trajectory categories.

ative humidity. Back trajectories can be also used to calculate a mean transportation speed over the last $72 \mathrm{~h}$. The mean air mass speed for the four main directories is plotted in Fig. 4. The maximum mean air mass speed of $8.9 \mathrm{~m} \mathrm{~s}^{-1}$ occurs again for NW and the minimum for local air masses is $2.1 \mathrm{~m} \mathrm{~s}^{-1}$. There is a factor of 4 between them describing a significant difference in the air mass history. Those air masses with higher average advection speed have less time to accumulate primary and secondary aerosol mass. Clean air arrives with faster moving transport winds from northern directions; more polluted air masses from southern directions arrive usually slower and spent more time in the Beijing area. There are two main reasons for this: the main industrial and other anthropogenic sources for aerosols and gases are located in the regions south of Beijing. The urban area itself is a major source for traffic emissions. In addition to this fact the air masses passing the southern regions are relatively slow, means they have much time to accumulate pollutants. The mean diurnal evolution of the local wind speed is shown in Fig. 5. The trend is similar within the four groups, i.e. the 


\section{Northwest}
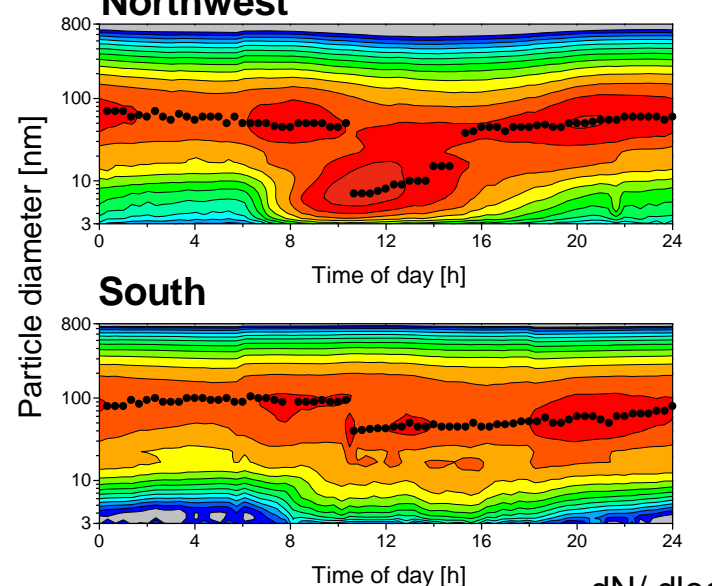

\section{Northeast}

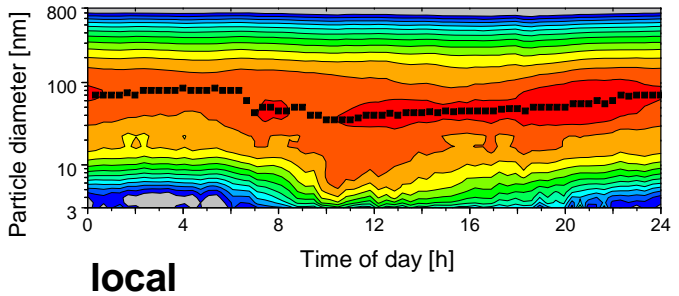

local

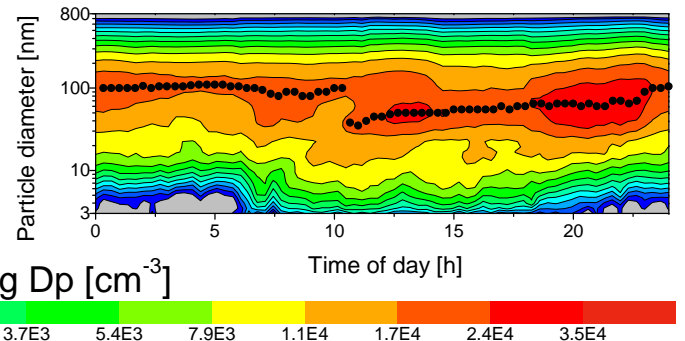

Fig. 6. Mean evolution of number size distribution divided into the selected air mass types. Black dots indicate the mean diameter of the dominating mode.
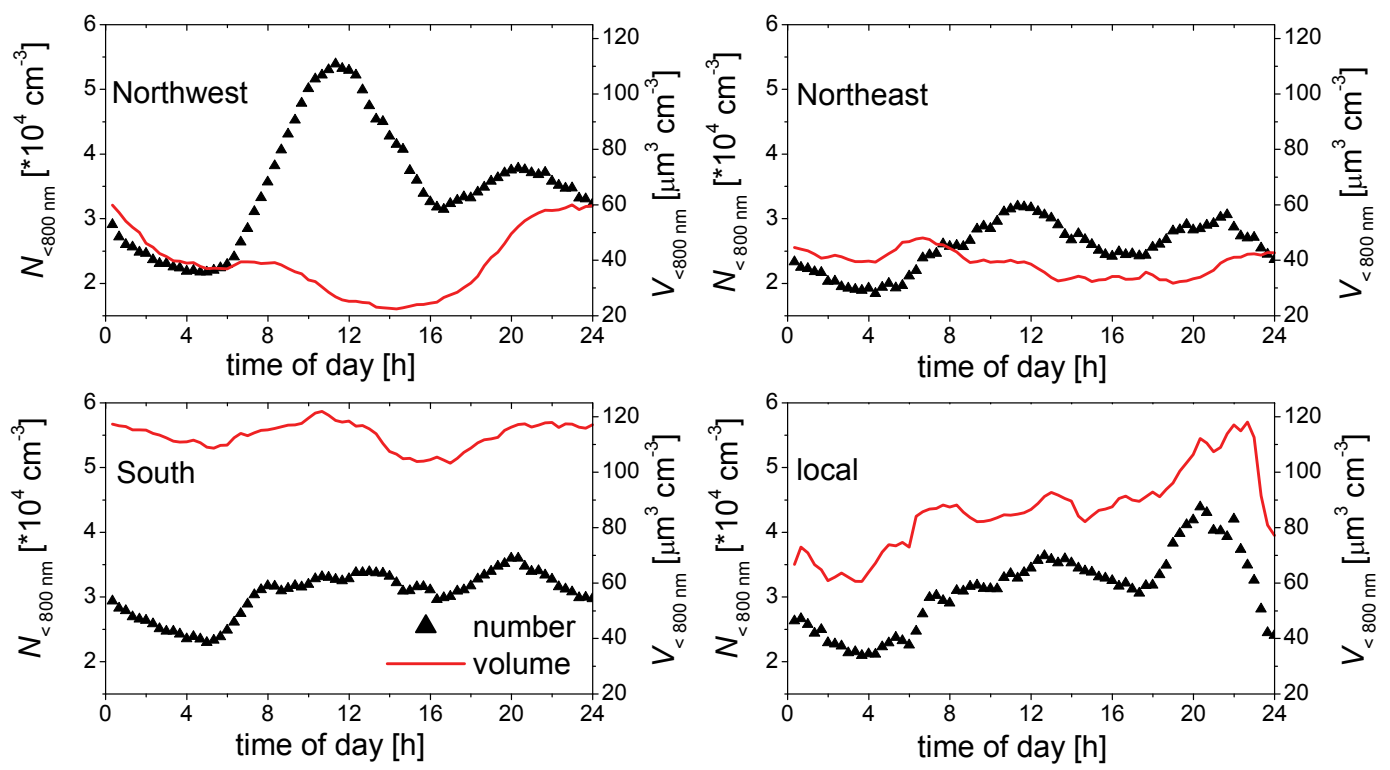

Fig. 7. Mean evolution of total number and volume concentration according to the selected air mass types.

wind speed is lowest during the night and highest between noon and early afternoon. The absolute values show however significant differences: for air masses from the northwest the maximum is around $3.3 \mathrm{~m} \mathrm{~s}^{-1}$, for the other three groups it is below $2 \mathrm{~m} \mathrm{~s}^{-1}$. This result indicates completely different meteorological situations. Clean air masses from the northwest lead to the development of a higher mixing layer with a greater local turbulent mixing, higher wind speeds, and subsequently to less accumulation of pollutants.
Figure 6 shows the mean evolution of number size distributions divided into the four types again. There are some differences in the diurnal variation recognizable: enhanced concentrations in the ultrafine fraction are recognizable for air masses from the northwest only. Air masses from other directions show one dominating accumulation mode with a maximum around $100 \mathrm{~nm}$ with slightly higher values in the night and morning hours. Integrated number and volume concentrations are shown in Fig. 7. Here, it becomes obvious that the connection between both is very different. Particle 
Table 1. Calculated parameters to represent number size distributions by 3 lognormal modes. The symbols mean: geometric mean diameters $D_{p}[\mathrm{~nm}]$, particle number concentration $N\left[\mathrm{~cm}^{-3}\right]$, and geometric standard deviation $\sigma$ for the three modes: mode $1=$ nucleation mode, mode $2=$ Aitken mode, mode $3=$ accumulation mode.

\begin{tabular}{crrrrrrrrc}
\hline Night & $D_{p 1}$ & $N_{1}$ & $\sigma_{1}$ & $D_{p 2}$ & $N_{2}$ & $\sigma_{2}$ & $D_{p 3}$ & $N_{3}$ & $\sigma_{3}$ \\
\hline NW & 17.9 & 7900 & 2.3 & 60 & 20000 & 1.9 & 165 & 7200 & 1.75 \\
S & 17.9 & 10100 & 1.7 & 63 & 17100 & 1.9 & 190 & 12000 & 1.75 \\
loc & 19.3 & 9000 & 1.8 & 68 & 18600 & 1.9 & 167 & 12200 & 1.75 \\
NE & 18.0 & 9900 & 1.7 & 63 & 19600 & 1.9 & 173 & 8800 & 1.75 \\
\hline Day & & & & & & & & & \\
NW & 8.0 & 28600 & 1.8 & 36 & 27700 & 1.9 & 135 & 7200 & 1.8 \\
S & 8.6 & 11300 & 1.8 & 37 & 22600 & 1.9 & 161 & 16800 & 1.8 \\
loc & 9.5 & 9900 & 1.8 & 45 & 26600 & 1.9 & 151 & 14300 & 1.8 \\
NE & 8.3 & 10900 & 1.9 & 39 & 25000 & 1.9 & 147 & 9400 & 1.8 \\
\hline
\end{tabular}

number and volume concentrations are nearly negatively correlated for air masses from the northwest, while they seem to be well correlated for air masses from the south and local ones. Figure 8 shows mean number size distributions according to the back trajectory categories averaged over two periods for day and night time with relatively stable number size distributions. In general, the maximum number concentrations at night time are lower and shifted to larger diameters compared to those during day time. The largest difference occurs for air masses from the northwest, because here new particle formation occurs during day time producing high number particle concentrations in the size range below $40 \mathrm{~nm}$. Obviously, there are no significant sources for ultrafine/Aitken particles in the night or the emissions do not reach the measurement site due to the stable stratification near the ground. During night time, size distributions are mainly dominated by the accumulation mode which is mainly caused by coagulation and growth due to condensation aqueous phase gas-to-particulate mass conversion of those particles which were emitted or formed during day time. The differences between individual air masses are less developed during nighttime, however the largest mean diameter occurs always for the local air masses and the smallest for those from the northeast. Thus a dominating accumulation mode represents always an indicator for the air mass origin consisting mainly of aged aerosol particles.

In an attempt to simplify the size distributions, trimodal lognormal functions were fitted to the experimental distributions shown in Fig. 8. We applied a moment-preserving least squares fitting algorithm that can principally accommodate up to five lognormal modes (Birmili et al., 2001). A particular feature of the algorithm is that not only particle number but also higher moments such as surface area and volume are preserved relatively accurately by the transformation. The results for the Beijing size distributions are shown in Table 1 giving geometric mean diameters $D_{p}$, particle number concentrations $N$, and geometric standard deviation $\sigma$ for each of the three lognormal modes (mode $1=$ nucleation mode,

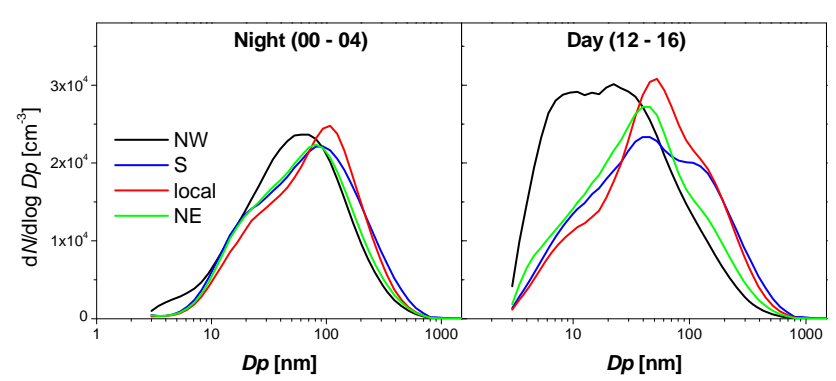

Fig. 8. Mean number size distributions averaged over two selected periods according to the selected air mass types: left side shows those during night time (00:00-04:00) and right side during day time (12:00-16:00).

mode 2 = Aitken mode, mode 3 = accumulation mode). A particular feature of the fit data is that the nucleation mode diameters tend to be significantly smaller during day-time as a result of photochemical secondary particle formation. On the other hand, all mean diameters tend to be slightly larger during night due to aging by coagulation and condensation.

\subsection{Back trajectory cluster analysis}

Besides the manual air mass classification above, a back trajectory cluster analysis was applied to the size distribution data set. Importantly, the cluster analysis considers the threedimensional transport features of the air mass (longitude, latitude, height above the ground, wind speed) across the length of an entire 3-day back trajectory. Here, we applied a kmeans cluster algorithm (Engler et al., 2007), which was developed closely following the approach first reported by Dorling et al. (1992). The existing trajectory data set is divided into a pre-defined number $\mathrm{k}$ of clusters with the goal of generating clusters that are as distinct from each other with respect to their mean values, but as homogeneously as possible within each cluster. Meteorologically speaking, the cluster 


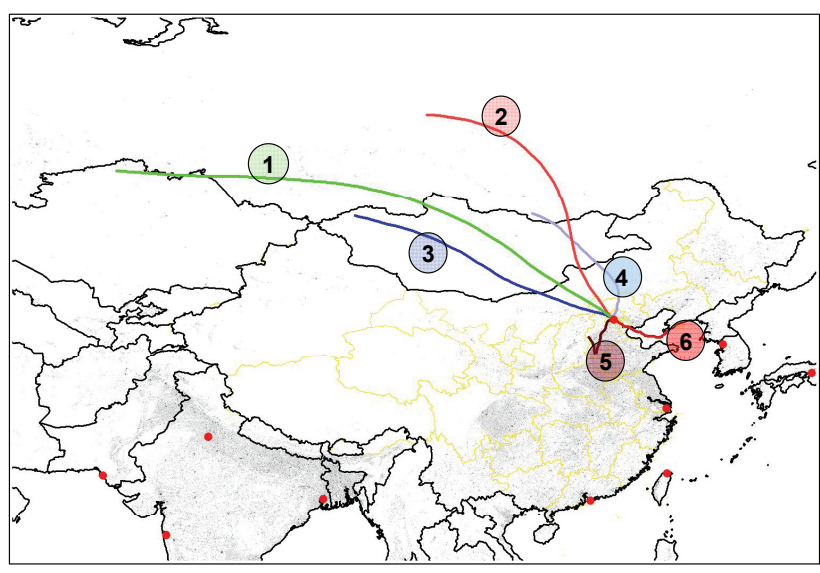

Fig. 9. Mean back trajectories for 6 trajectory clusters arriving at Beijing 2004-2006. Red dots mark cities with >5 Mio. inhabitants, grey shading indicates areas of high population density.

analysis aims at classifying and separating the weather situations governing the receptor site as distinctively as possible. A distance measure between different trajectories was defined that accounts for differences in geographical latitude, longitude, and height above the ground. Straight radial trajectories were used as initial seed trajectories. For each day, one single trajectory was employed terminating in Beijing at 12:00 $\mathrm{h}$ local time (LT). The corresponding size distribution data were averaged over the period 10:00-18:00 $\mathrm{h} \mathrm{LT}$, which is the time when the urban measurements correspond best to the conditions in the well-mixed large-scale air mass.

The final number of clusters provided by the analysis needs to be determined for each data set individually and represents a compromise between an optimum separation of the size distribution data set (larger number of clusters), and simplicity of display (lower number of clusters). Several runs of the clustering algorithm using different orientations with respect to the seed trajectories suggested an optimum number of 6 trajectory clusters for the Beijing site. Any lower number of clusters did not fully represent the variety of trajectories in terms of their wind speed and direction, whereas higher numbers did create superfluous information, such as clusters with mean trajectories very close to each other. Figure 9 shows the mean back trajectories for the six clusters. Each of the clusters represents between 88 and 108 (out of $575)$ individual days. The mean back trajectories show significant differences in direction but also in length, and therefore represent the main classes of atmospheric flow conditions over north-eastern China. The two short trajectory clusters 5 and 6 arrive from southerly directions, while the other four approach from the north-westerly section. Winds from southerly directions are usually connected with two main circulation patterns: Either a high pressure system south of Beijing, which leads to an inversion situation and slow winds

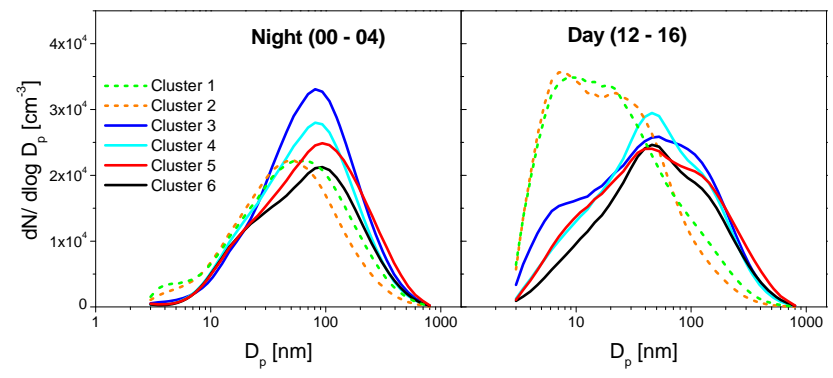

Fig. 10. Mean number size distributions fort the six clusters, according to the classification in Fig. 9.

from southerly directions, or a low pressure system over the Indian Ocean, which transports humid air over the Chinese coastal areas at low wind speeds. As the Chinese mainland south of Beijing is generally densely populated, southerly air masses may be heavily polluted once they arrive at Beijing. Northerly and north-easterly winds, as represented by clusters $1-4$, are typically connected with high pressure centered over central China and low pressure over the northern Pacific. These situations lead to the advection of dry and continental air into the Beijing area.

Figure 10 shows the mean number size distribution for each cluster and reveals a general dichotomy in the data set: The size distributions of cluster 1 and 2 (day) are characterized by a number concentration maximum around $40 \mathrm{~nm}$, low concentrations in the accumulation mode, but significant numbers of particles $<30 \mathrm{~nm}$. All other clusters, in contrast, are characterized by a clear size distribution maximum around $80 \mathrm{~nm}$, which is indicative of significant anthropogenic influence. Of these, clusters 3 and 4 show the highest concentrations in the accumulation mode range $(>100 \mathrm{~nm})$ for day and night, while cluster 5 shows the highest concentration in the range above $250 \mathrm{~nm}$. An et al. (2007) modeled a five day pollution episode in terms of $\mathrm{PM}_{2.5}, \mathrm{PM}_{10}$, and $\mathrm{SO}_{2}$, which corresponded to a similar weather situation represented by cluster 5 . The transport model suggested that non-Beijing pollution sources played an overwhelming role during the period. This implies that the high concentrations of accumulation mode aerosol in clusters 5 and 6 result from the uptake of anthropogenic pollution aerosol across the wider region south of Beijing. The clusters 1-4 arrive from north-westerly directions and lead - depending on the transportation speed - to variable degrees of particulate pollution in Beijing. A main controlling factor seems to be the residence time of an air mass over the North China Plain, i.e. the populated lowlands surrounding Beijing: While the slow wind speed clusters 3 and 4 show particle size distributions very similar to the most polluted clusters 5 and 6 , the high wind speed clusters show the lowest accumulation mode concentration at all. It can be concluded here that fast air masses from Central Asia lead to the lowest particle mass 


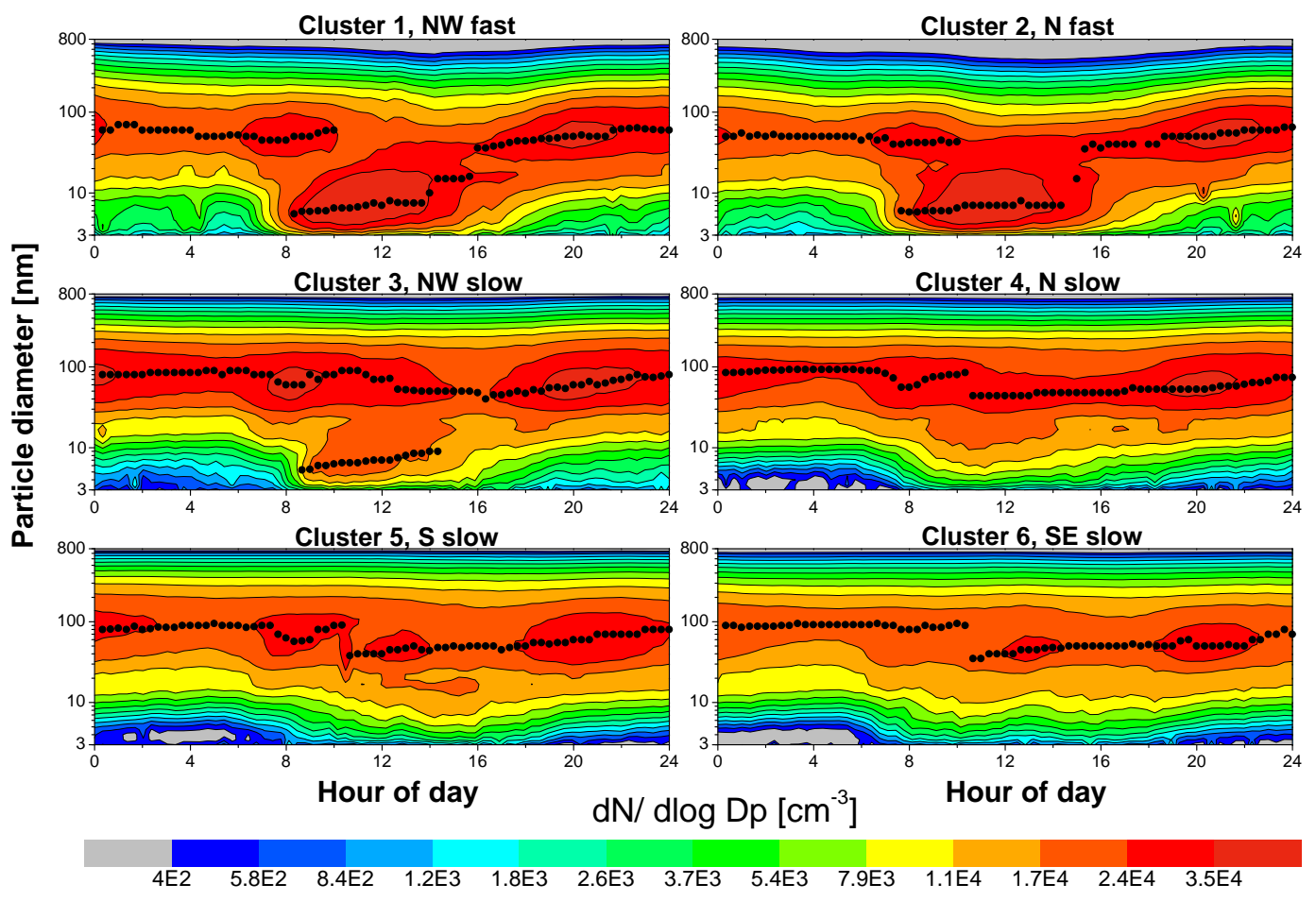

Fig. 11. Diurnal variation of number size distributions averaged over all days belonging to the same cluster. Black dots indicate the mean diameter of the dominating mode.

concentrations observable in Beijing. Figure 11 shows contour diagrams of the diurnal variation of number size distributions, averaged for each of the trajectory clusters introduced in Fig. 9. Significant differences are recognizable: Clusters 3 and 4 show their highest number concentrations around a particle size of $100 \mathrm{~nm}$. This maximum diameter is relatively stable during whole day with an additional small shoulder in the morning in the ultrafine range indicating few events of new particle formation. In contrast, the two clusters with fast air mass transport from the north and northwest (clusters 1 and 2) show a clear ultrafine mode in the late morning growing into the Aitken mode at noon indicating frequent events of new particle formation. The two clusters representing the very short back trajectories from the south (clusters 5 and 6) do not show any indication of new particle formation; in fact, particle formation events were observed on six days of cluster 5 and two days of cluster 6 only, all belonging to the polluted case as introduced by $\mathrm{Wu}$ et al. (2007). The diurnally averaged time series of the total number and volume concentration are shown in Fig. 12. The general differences in particles characteristics are obvious again: cluster 1 and 2 show strongly negatively correlated number and volume concentration, this trend is less clear for 3 and 4 and for the two more polluted clusters 5 and especially 6 number and volume are partly correlated. This indicates a strong influence of the boundary layer development and cor- responding dilution during day for clean cases creating the decrease in volume concentration followed by the production of new particles creating the increase in number concentration. These particles are typically below $50 \mathrm{~nm}$ in diameter, and thus, they have a small influence on volume concentration. During more polluted cases in Beijing both boundary layer development and new particle formation are suppressed and directly emitted particles $>50 \mathrm{~nm}$ or particles grown into that size range dominate the number size distributions. These particles have a significant influence on the particle volume concentration. Similar to Sect. 3.2., lognormal parameters were calculated for the size distributions shown in Fig. 10. The lognormal parameters are shown in Table 2. It is worth to note that the back trajectory analysis provides a refined picture on the controlling factors.

Table 3 displays the mean values for selected parameters such as $\mathrm{PM}_{1}$ mass concentration as well as meteorological characteristics. The highest mass concentration of $168 \mu \mathrm{g} \mathrm{m}^{-3}$ occurred in cluster 5 representing slow air masses from the south, while the lowest concentrations (66 and $42 \mu \mathrm{g} \mathrm{m}^{-3}$ ) were associated with northerly advection (clusters 1 and 2). The average PBL depth for the six clusters varied between 820 and $1400 \mathrm{~m}$, with the highest values occurring in the clean northerly air masses (clusters 1 and 2). Notably, the mass concentration is negatively correlated to the PBL depth, which we see as an indication of pollution 

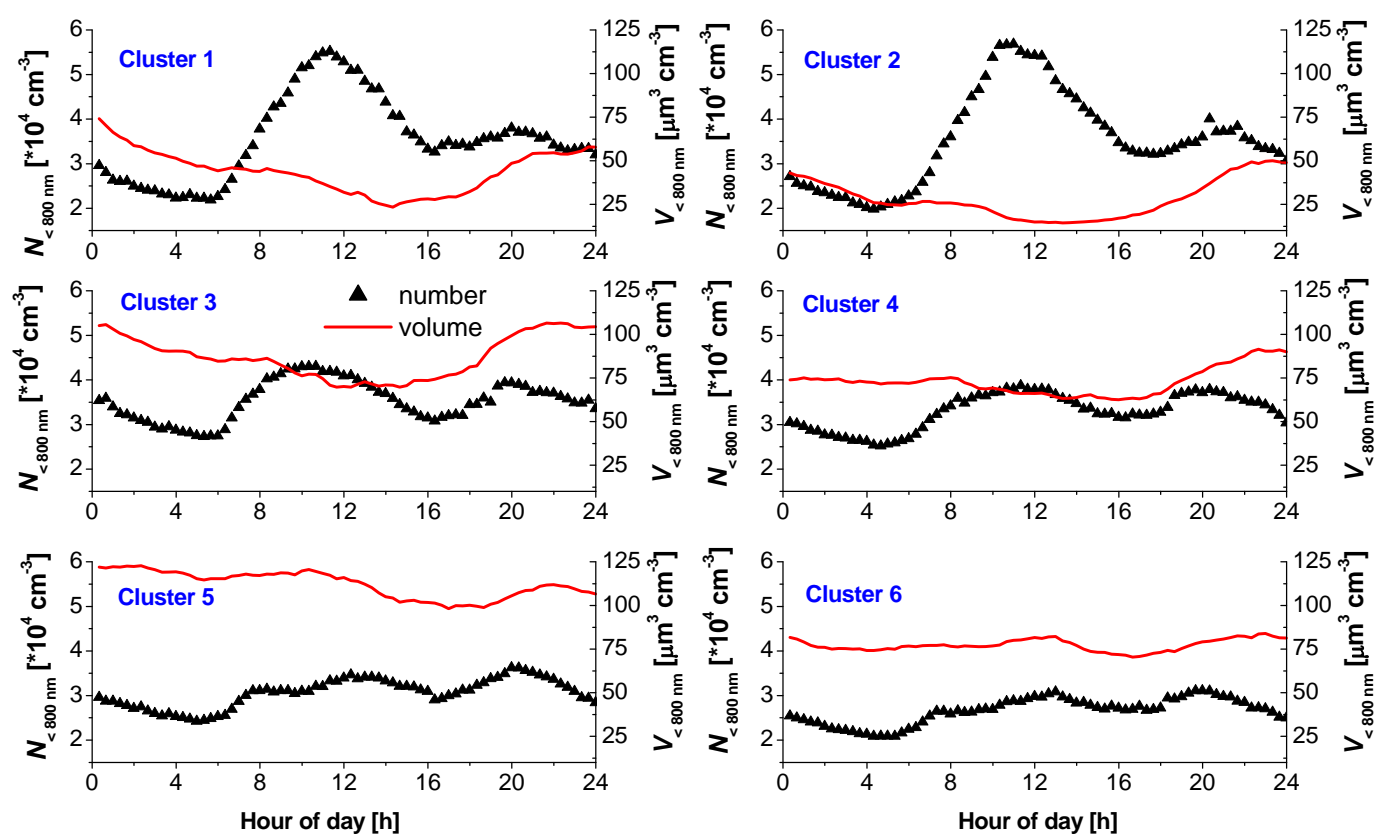

Fig. 12. Diurnal variation of total number and volume concentration averaged over all days belonging to the same cluster.

Table 2. Calculated parameters to represent mean number size distributions from cluster analysis by 3 lognormal modes. The symbols mean: geometric mean diameters $D_{p}[\mathrm{~nm}]$, particle number concentration $N\left[\mathrm{~cm}^{-3}\right]$, and geometric standard deviation $\sigma$ for the three modes: mode 1 = nucleation mode, mode $2=$ Aitken mode, mode $3=$ accumulation mode .

\begin{tabular}{crrrrrrrrr}
\hline Night & $D_{p 1}$ & $N_{1}$ & $\sigma_{1}$ & $D_{p 2}$ & $N_{2}$ & $\sigma_{2}$ & $D_{p 3}$ & $N_{3}$ & $\sigma_{3}$ \\
\hline Cluster 1 & 12.0 & 9400 & 1.8 & 54 & 23000 & 1.85 & 184 & 8900 & 1.7 \\
Cluster 2 & 12.0 & 8000 & 1.9 & 55 & 22700 & 1.85 & 183 & 5100 & 1.7 \\
Cluster 3 & 19.2 & 7500 & 1.9 & 75 & 30800 & 1.85 & 205 & 9300 & 1.7 \\
Cluster 4 & 20.1 & 10100 & 1.8 & 80 & 28100 & 1.85 & 227 & 5400 & 1.7 \\
Cluster 5 & 16.5 & 8000 & 1.7 & 75 & 24000 & 1.85 & 224 & 10500 & 1.7 \\
Cluster 6 & 17.0 & 8300 & 1.7 & 71 & 19000 & 1.85 & 199 & 8800 & 1.7 \\
\hline Day & $D_{p 1}$ & $N_{1}$ & $\sigma_{1}$ & $D_{p 2}$ & $N_{2}$ & $\sigma_{2}$ & $D_{p 3}$ & $N_{3}$ & $\sigma_{3}$ \\
\hline Cluster 1 & 8.8 & 35500 & 1.9 & 35 & 20400 & 1.9 & 118 & 9800 & 1.8 \\
Cluster 2 & 8.1 & 35200 & 1.8 & 38 & 25100 & 1.9 & 156 & 2700 & 1.8 \\
Cluster 3 & 7.5 & 14900 & 1.8 & 45 & 27100 & 1.9 & 160 & 12300 & 1.8 \\
Cluster 4 & 9.0 & 11900 & 1.7 & 43 & 27200 & 1.9 & 148 & 14000 & 1.8 \\
Cluster 5 & 10.9 & 13700 & 1.9 & 47 & 22100 & 1.9 & 173 & 14800 & 1.8 \\
Cluster 6 & 12.5 & 10400 & 1.9 & 48 & 21300 & 1.9 & 158 & 13000 & 1.8 \\
\hline
\end{tabular}

trapping during situations of less intense vertical exchange. According to the different lengths of the back trajectories, which were obvious from Fig. 9, the air mass speed show significant differences too: the shortest trajectories (clusters 5 and 6) had a mean speed of $0.7 \mathrm{~m} \mathrm{~s}^{-1}$ while the fastest one (cluster 1) had a mean transportation speed of $6.4 \mathrm{~m} \mathrm{~s}^{-1}$, i.e. there is almost a factor of 10 between them. This means the slowest air mass spends at least $20 \mathrm{~h}$ within an area $50 \mathrm{~km}$ around the measurement site, while the fastest one only $2 \mathrm{~h}$.
Particle mass concentration shows also a negative correlation with the mean speed of the air mass, i.e. high mass concentrations are connected with low air mass speed and vice versa. A faster moving air mass will accumulate fewer pollutants during its shorter transit time across a source area. For Beijing, this effect is emphasized by the fact that fast moving air masses arrive from the north, where sources are more scarce. Air masses associated with shorter back trajectories (from the south) spend more time in polluted areas and 
Table 3. Mean values of selected parameters for the six clusters: mass concentration $<1 \mu \mathrm{m}\left(\mathrm{PM}_{1}\right)$, boundary layer depth (PBL), air mass speed $(v)$, visibility $(v i s)$, temperature $(T)$, relative humidity $(r H)$, and global radiation $(\mathrm{rad})$.

\begin{tabular}{lrrrrrrr}
\hline & $\begin{array}{r}\mathrm{PM}_{1} \\
{\left[\mu \mathrm{g} \mathrm{m}^{-3}\right]}\end{array}$ & $\begin{array}{r}\mathrm{PBL} \\
{[\mathrm{m}]}\end{array}$ & $\begin{array}{r}v \\
{\left[\mathrm{~m} \mathrm{~s}^{-1}\right]}\end{array}$ & $\begin{array}{r}\text { vis } \\
{[\mathrm{m}]}\end{array}$ & $\begin{array}{r}T \\
{\left[{ }^{\circ} \mathrm{C}\right]}\end{array}$ & $\begin{array}{r}r H \\
{[\%]}\end{array}$ & $\begin{array}{r}\text { rad } \\
{\left[\mathrm{W} \mathrm{m}^{-2}\right]}\end{array}$ \\
\hline Cluster 1 & 66 & 1400 & 6.4 & 15620 & 9.3 & 33 & 246 \\
Cluster 2 & 42 & 1400 & 3.5 & 19860 & 11.8 & 33 & 275 \\
Cluster 3 & 130 & 940 & 3.3 & 9100 & 7.2 & 33 & 218 \\
Cluster 4 & 109 & 1030 & 1.7 & 9810 & 15.6 & 45 & 188 \\
Cluster 5 & 168 & 820 & 0.7 & 5420 & 21.9 & 51 & 93 \\
Cluster 6 & 116 & 940 & 0.7 & 5900 & 22.8 & 58 & 84 \\
\hline
\end{tabular}

are thus more influenced by regional and local emissions and secondary aerosol production. As obvious from Table 3 also visibility and $\mathrm{PM}_{1}$ are negatively correlated. The visibility shows its maximum of $20 \mathrm{~km}$ for cluster 2 followed by cluster 1 with $15.6 \mathrm{~km}$. The visibility was lowest for cluster 5 and 6 with 5.9 and $5.4 \mathrm{~km}$. These findings emphasize again the characteristics of the different air masses: cleanest air, which is characterized by low mass concentrations and high visibility arrives fast from northern directions, while more polluted air showing higher $\mathrm{PM}_{1}$ and low visibility is arriving slower from the south.

Figure 13 shows daytime values for the PBL depth and calculated volume concentration leading to more detailed conclusions than the averages in Table 3. Different colors and symbols are used to represent the corresponding clusters. This figure illustrates clearly the anti-correlation between the boundary layer depth (PBL) and the particle volume concentration, here representing the regional air pollution. Low particulate volume (or mass) concentrations always correspond to effective vertical mixing conditions. For instance, the highest PBL depths of more than $1500 \mathrm{~m}$ are always associated volume concentrations $<50 \mu \mathrm{m}^{3} \mathrm{~cm}^{-3}$ and occur for cluster 1 and 2 only. The reverse conclusion is not true; days with low PBL depths feature both high and low volume concentrations for all clusters. The figure illustrates clearly that lower volume concentration (and high PBL depths) occurs mainly on days, which belong to cluster 1 or 2 , while higher volume concentrations and low PBL depths are more frequent for clusters 3-6.

Averages of meteorological data for the 6 cluster types (Table 3) show also significant differences. The temperature is highest for clusters 5 and $6\left(22.8\right.$ and $\left.21.9^{\circ} \mathrm{C}\right)$ representing air masses from the south and lowest for air masses from the northwest ( 3 and 1 with 7.2 and $9.3^{\circ} \mathrm{C}$ ). This finding is probably a result of the location of the air mass 3 days prior to its arrival at the measuring site and also the synoptic weather pattern and the time of the year when these trajectories have been observed. The polluted air masses from the south are thus more frequent in summer, while during winter time the air masses are coming more frequent from the northwest. The measured global radiation shows the oppo-

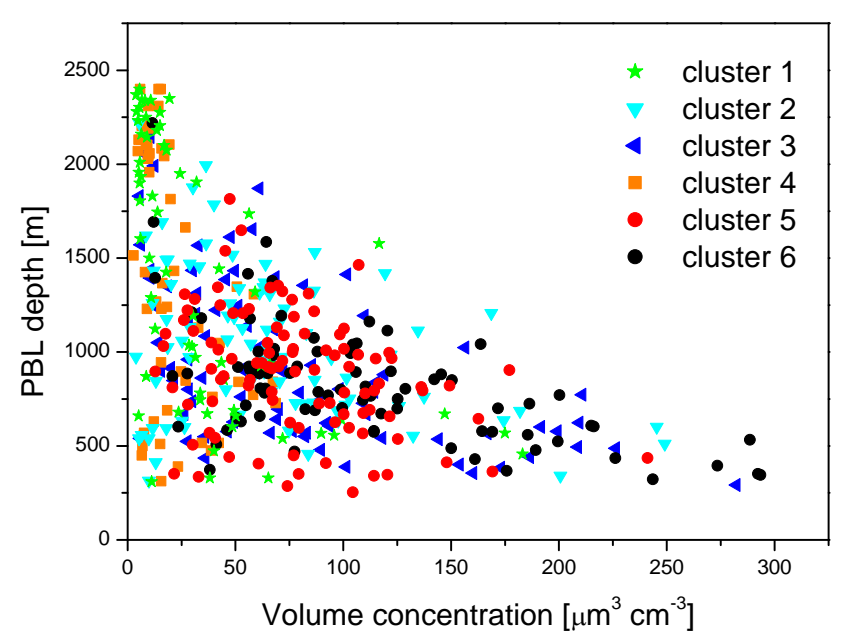

Fig. 13. Relation between boundary layer depth (PBL) and calculated volume concentration represented by averages during daytime only (10:00-16:00). Different colors and symbols represent different clusters.

site behavior: it is lowest for 5 and 6 , i.e. during high temperatures and highest during low temperatures. To explain this behavior, the general pollution situation has to be considered: cluster 5 and 6 show the highest particle mass concentration with the lowest visibility leading to a significant reduction in global radiation. The effect of visibility reduction is thus stronger than the fact that these cases occur mostly in summer, when more global radiation should reach the atmosphere. The overall result agrees well with the findings of Xia et al. (2007). They analyzed 5 years of back trajectories in connection with data of the aerosol optical depth (AOD) using the method of cluster analysis. Trajectories were also classified into 6 clusters separating fast from slowly moving air masses but in addition split by season. The main result was that the fast moving north-westerly air masses were basically associated with lower AOD except in spring because of desert dust influence. 


\section{Conclusions}

Long-term measurements since 2004 of atmospheric particle number size distributions $(0.003-10 \mu \mathrm{m})$ have confirmed the region of Beijing, China as a global hot spot of particulate air pollution. Such in-situ aerosol measurements have been, to our knowledge, unique on the densely populated southeast Asian mainland with respect to their duration and particle size range covered. For the period between 2004 and 2006 the mean concentrations of particle number, surface, and volume concentration were $32800 \mathrm{~cm}^{-3}, 1400 \mu \mathrm{m}^{2} \mathrm{~cm}^{-3}$, and $90 \mu \mathrm{m}^{3} \mathrm{~cm}^{-3}$, respectively. The Beijing number concentrations are only $\sim 30 \%$ higher than the values observed in European or North American cities but the mass concentration exceeds the values at polluted sites in Europe by a factor of three. This is indicative of two processes: First, the sizedependent profile of primary aerosol emissions might be different in current China compared to Europe. Second, the higher surface area encountered in the Beijing atmosphere acts as a more effective coagulation sink for nucleation mode particles. Clear indications of a delineation of nucleation and accumulation mode particles were in fact found within the Beijing data set itself (see Fig. 10).

Two different classification schemes were applied to characterize the history of the air masses arriving at Beijing. A simplistic categorization of trajectories yielded differences in mean particle mass concentration by a factor of two between southerly and northerly air masses. This result is qualitatively in agreement with an increased residence time of the air over densely populated areas along with different traveling speeds (the mean wind speed in southerly air masses was by a factor of 3.5 lower than in northerly air masses). The analysis in connection with the results from Wu et al. (2008) suggests that variations of aerosol parameters along with the air mass history are more significant than the seasonal, weekly or even diurnal cycles. The highest seasonal average of $\mathrm{PM}_{10}$ mass concentration was found with $149 \mu \mathrm{g} \mathrm{m}^{-3}$ in autumn, the lowest one with $115 \mu \mathrm{g} \mathrm{m}^{-3}$ in spring. An average $\mathrm{PM}_{10}$ concentration of $206 \mu \mathrm{g} \mathrm{m}^{-3}$ was found for southerly air masses, but only $94 \mu \mathrm{g} \mathrm{m}^{-3}$ for northeasterly air masses from inner Asia.

The picture was enhanced by a back trajectory cluster analysis, which is not only sensitive to wind direction but wind speed and vertical trajectory motion. According to this analysis the highest particle mass concentrations prevailed in slow air masses, particularly those originating in the densely populated regions south of Beijing. Low particle mass concentrations, in contrast, were found in air from the high Central Asian plains. On the one hand, these plains are sparsely populated while on the other hand, air from those regions usually travels at higher speeds $\left(\sim 6.5 \mathrm{~m} \mathrm{~s}^{-1}\right)$. The transport of air from the Central Asian plains is usually facilitated by stationary high pressure systems that reside over central China in winter. More polluted situations are connected with high pressure systems south of Beijing leading to an inver- sion with slow southern wind or the so-called monsoon transporting humid air over the coastal areas mainly during the summer months. The mean transportation speeds in the latter situations are typically below $1 \mathrm{~m} \mathrm{~s}^{-1}$. Different air masses and their levels of $\mathrm{PM}_{1}$ and $\mathrm{PM}_{10}$ were also associated with different degrees of atmospheric visibility: For two trajectory clusters coming from the north, for example, the $\mathrm{PM}_{1}$ mass concentration and visibility co-varied by a factor of approximately two. Comparing the two methods can be concluded that the differences found by cluster analysis being the more objective method are more significant than those by the simple air mass direction classification. Thus such studies should be based on as many characteristics as possible not only on the direction of back trajectories. Overall the results of both methods are in good agreement but this study illustrates in addition potential differences obtained by the different methods. One major finding from the cluster analysis is that the pollution level in the Beijing region depends not only on the direction of arriving air mass but also on its transportation speed. This result could not be obtained from the first method alone.

High concentrations of small particles $\left(D_{p}<30 \mathrm{~nm}\right)$ were found predominantly in clean northerly air masses. A likely explanation for the nucleation mode in northerly air masses is its efficient vertical dilution and therefore relatively low pre-existing particle surface area. Our impression is that in the Beijing area the formation of new particles $\left(D_{p}<40 \mathrm{~nm}\right)$ from gaseous precursors is never limited by the precursor concentrations but rather the pre-existing population of larger particles that act as a coagulation sink.

A salient conclusion is that the levels of particle mass and number in Beijing are not always of a high level, but depend strongly on the synoptic scale meteorological situation. This finding has considerable implications for air quality regulation. Any local emission reduction measures, such as traffic reductions of temporary close-downs of industrial plants may have only negligible impact when the air mass is stagnant, or when being transported from southerly directions.

Acknowledgements. The authors thank all co-workers from IfT and State Key Lab for their help in installing and operating the instruments. This work was supported by the National Natural Science Foundation of China (204100XX) and the National Basic Research Program (2002CB211605) and the DFG (WI 14449/9-1), Germany. The data evaluation for this paper was conducted within the European Integrated project on Aerosol Cloud Climate and Air Quality Interactions (EUCAARI), coordinated by the University of Helsinki, Finland.

Edited by: V.-M. Kerminen 


\section{References}

An, X., Zhu, T., Wang, Z., Li, C., and Wang, Y.: A modeling analysis of a heavy air pollution episode occurred in Beijing, Atmos. Chem. Phys., 7, 3103-3114, 2007, http://www.atmos-chem-phys.net/7/3103/2007/.

Analitis, A., Katsouyanni, K., Dimakopoulou, K., Samoli, E., Nikoloulopoulos, A. K., Petasakis, Y., Touloumi, G., Schwartz, J., Anderson, H. R., Cambra, K., Forastiere, F., Zmirou, D., Vonk, J. M., Clancy, L., Kriz, B., Bobvos, J., and Pekkanen, J.: Short-term effects of ambient particles on cardiovascular and respiratory mortality, Epidemiology, 17(2), 230-233, 2006.

Birmili, W., Stratmann, F., and Wiedensohler, A.: Design of a DMA-based Size Spectrometer for large particle size range and stable operation, J. Aerosol Sci., 30, (4), 549-554, 1999.

Birmili, W., Wiedensohler, A., Heintzenberg, J., and Lehmann, K.: Atmospheric particle number size distribution in Central Europe: Statistical relations to air masses and meteorology, J. Geophys. Res., 106(D23), 32 005-32 018, 2001.

Draxler, R. R. and Rolph, G. D.: HYSPLIT (Hybrid Single-Particle Lagrangian Integrated Trajectory) Model access via NOAA ARL READY Website: http://www.arl.noaa.gov/ready/hysplit4.html, NOAA Air Resources Laboratory, Silver Spring, MD, 2003.

Dominici, F., McDermott, A., Daniels, M., Zeger, S. L., and Samet, J. M.: Revised analyses of the National Morbidity, Mortality, and Air Pollution Study: mortality among residents of 90 cities, J. Toxicol. Environ. Health A, 68(13-14), 1071-1092, 2005.

Dominici, F., Peng, R. D., Bell, M. L., Pham, L., McDermott, A., Zeger, S. L., and Samet, J. M.: Fine particulate air pollution and hospital admissions for cardiovascular and respiratory deseases, JAMA, 295, 1127-1134, 2006.

Dorling, S. R., Davies, T. D., and Pierce, C. E.: Cluster analysis: a technique for estimating the synoptic meteorological controls on air and precipitation chemistry - method and applications, Atmos. Environ., 26A, 2575-2581, 1992.

Engler, C., Rose, D., Wehner, B., Wiedensohler, A., Brggemann, E., Gnauk, T., Spindler, G., Tuch, T., and Birmili, W.: Size distributions of non-volatile particle residuals $\left(D_{p}<800 \mathrm{~nm}\right)$ at a rural site in Germany and relation to air mass origin, Atmos. Chem. Phys., 7, 5785-5802, 2007, http://www.atmos-chem-phys.net/7/5785/2007/.

Florig, H. K., Sun, G., and Song, G.: Evolution of particulate regulation in China-prospects and challenges of exposure-based control, Chemosphere, 49(9), 1163-1174, 2002.

Franklin, M., Zeka, A., and Schwartz, J.: Association between $\mathrm{PM}_{2.5}$ and all-cause and specific-cause mortality in 27 US communities, J. Expos. Sci. Environ. Epidemiol., 17(3), 279-287, 2006.

Guinot, B., Roger, J.-C., Cachier, H., Pucai, W., Jianhui, B., and Tong, Y.: Impact of vertical atmospheric structure on Beijing aerosol distribution, Atmos. Environ., 40, 5167-5180, 2006.

Guinot, B., Cachier, H., Sciare, J., Tong, Y., Xin, W., and Jianhua, Y.: Beijing aerosol: Atmospheric interactions and new trends, J. Geophys. Res., 112, D14314, doi:10.1029/2006JD008195, 2007.

Han, L., Zhuang, G., Cheng, S., Wang, Y., and Li, J.: Characteristics of re-suspended road dust and its impact on the atmospheric environment in Beijing, Atmos. Environ., 41, 7485-7499, 2007.

Huang, X.-F., Hu, M., He, L.-Y., and Tang, X.-Y.: Chemical characterization of water-soluble organic acids in $\mathrm{PM}_{2.5}$ in Beijing, China, Atmos. Environ., 39, 2819-2827, 2005.
Kan, H., London, S. J., Chen, G., Zhang, Y., Song, G., Zhao, N., Jiang, L., and Chen, B.: Differentiating the effects of fine and coarse particles on daily mortality in Shanghai, China, Environ. Int., 33(3), 376-384, 2007.

Kaiser, D. P. and Qian, Y.: Decreasing trends in sunshine duration over China for 1954-1998: Indication of increased haze pollution?, Geophys. Res. Lett., 29, 2042, doi:10.1029/2002GL016057, 2002.

Kettunen, J., Lanki, T., Tiittanen, P., Aalto, P. P., Koskentalo, T., Kulmala, M., Salomaa, V., and Pekkanen, J.: Associations of fine and ultrafine particulate air pollution with stroke mortality in an area of low air pollution levels, Stroke, 38(3), 918-922, 2007.

Lawrence, M. G., Butler, T. M., Steinkamp, J., Gurjar, B. R., and Lelieveld, J.: Regional pollution potentials of megacities and other major population centers, Atmos. Chem. Phys., 7, 39693987, 2007,

http://www.atmos-chem-phys.net/7/3969/2007/.

Li, X., Kikuo, O., Peng, Z., Daizhou, Z., and Guangyu, S.: An Observational Study of Physical and Chemical Characteristics of Atmospheric Aerosol Particles from Late Spring to Early Autumn over the Beijing Area, Chinese Journal of Atmospheric Sciences, 26(3), 401-411, 2002.

Massling, A., Stock, M., Tuch, T., Wehner, B., Wu, Z., and $\mathrm{Hu}$, M.: Size-segregated determination of differently hygroscopic particle fractions and soluble volume size distributions of the urban submicrometer Beijing aerosol, Atmos. Environ., 42, doi:10.1016/j.atmosenv.2008.06.003, in press, 2008.

Ostro, B., Broadwin, R., Green, S., Feng, W. Y., and Lipsett, M.: Fine particulate air pollution and mortality in nine California counties: Results from CALFINE, Environ. Health Persp., 114(1), 29-33, 2006.

Peters, A., Dockery, D. W., Muller, J. E., and Mittleman, M. A.: Increased particulate air pollution and the triggering of myocardial infarction, Circulation, 103, 2810-2815, 2001.

Peters, A., Schneider, A., Greven, S., Bellander, T., Forastiere, F., Ibald-Mulli, A., Illig, T., Jacquemin, B., Katsouyanni, K., Koenig, W., Lanki, T., Pekkanen, J., Pershagen, G., Picciotto, S., Ruckerl, R., Rosario, A. S., Stefanadis, C., and Sunyer, J.: Air pollution and inflammatory response in myocardial infarction survivors: gene-environment interactions in a high-risk group, Inhal. Toxicol., 19(1), 161-175, 2007.

Qian, Z., He, Q., Lin, H. M., Kong, L., Liao, D., Dan, J., Bentley, C. M., and Wang, B.: Association of daily cause-specific mortality with ambient particle air pollution in Wuhan, China, Environ. Res., 105(3), 380-389, 2007a.

Qian, W., Fu, J., and Yan, Z.: Decrease of light rain events in summer associated with a warming environment in China during 1961-2005, Geophys. Res. Lett., 34, L11705, doi:10.1029/2007GL029631, 2007b.

Ruckerl, R., Phipps, R. P., Schneider, A., Frampton, M., Cyrys, J., Oberdorster, G., Wichmann, H. E., and Peters, A.: Ultrafine particles and platelet activation in patients with coronary heart disease - results from a prospective panel study, Part Fibre. Toxicol., 173(4), 432-441, 2007.

Ruuskanen, J., Tuch, Th., ten Brink, H., Peters, A., Khlystov, A., Mirme, A., Kos, G. P. A., Brunekreef, B., Wichmann, H. E., Buzorius, G., Vallius, M., Kreyling, W. G., and Pekkanen, J.: Concentrations of ultrafine, fine and $\mathrm{PM}_{2.5}$ particles in three Eu- 
ropean cities, Atmos. Environ., 35, 3729-3738, 2001.

Schwartz, J. and Neas, L. M.: Fine particles are more strongly associated than coarse particles with acute respiratory health effects in schoolchildren [see comments], Epidemiology, 11(1), 6-10, 2000.

Shao, M., Tang, X., Zhang, Y., and Li, W.: City clusters in China: air ad surface water pollution, Front Ecol. Environ., 4, 353-361, 2006.

Stanier, C. O., Khlystov, A. Y., and Pandis, S. N.: Nucleation events during the Pittsburgh Air Quality study: Description and relation to key meteorological, gas phase, and aerosol parameters, Aerosol Sci. Technol., 38, 253-264, 2004.

Stölzel, M., Breitner, S., Cyrys, J., Pitz, M., Wolke, G., Kreyling, W., Heinrich, J., Wichmann, H., and P. E., A.: Daily mortality and particulate matter in different size classes in Erfurt, Germany, J. Expo. Sci. Environ. Epidemiol., 17(5), 458-467, 2007.

Streets, D. G., Gupta, S., Waldhoff, S. T., Wang, M. Q., Bond, T. C., and Yiyun, B.: Black carbon emissions in China, Atmos. Environ., 35, 4281-4296, 2001.

Sugimoto N., Uno, I., Nishikawa, M., Shimizu, A., Matsui, I., Dong, X., Chen, Y., and Quan, H.: Record Heavy Asian Dust in Beijing in 2002: Observations and Model Analysis of Recent Events, Geophys. Res. Lett., 30(12), 1640, doi:10.1029/2002GL016349, 2003.

Tuch, T. M., Wehner, B., Pitz, M., Cyrys, J., Heinrich, J., Kreyling, W. G., Wichmann, H. E., and Wiedensohler, A.: Long-term measurements of size-segregated ambient aerosol in two German cities located $100 \mathrm{~km}$ apart, Atmos. Environ., 37, 4687-4700, 2003.

van Dingenen, R., Raes, F., Putaud, J.-P., Baltensperger, U., Charron, A., Facchini, M.-C., Decesari, S., Fuzzi, S., Gehrig, R., Hansson, H.-C., Harrison, R. M., Hüglin, C., Jones, A. M., Laj, P., Lorbeer, G., Maenhaut, W., Palmgren, F., Querol, X., Rodriguez, S., Schneider, J., ten Brink, H., Tunved, P., Tørseth, K., Wehner, B., Weingartner, E., Wiedensohler, A., and Wåhlin, P.: A European aerosol phenomenology 1: Physical characteristics of particulate matter at kerbside, urban, rural and background sites in Europe, Atmos. Environ., 38, 2561-2577, 2004.

Wang, Y., Zhuang, G. S., Tang, A. H., Yuan, H., Sun, Y. L., Chen, S. A., and Zheng, A. H.: The ion chemistry and the source of $\mathrm{PM}_{2.5}$ aerosol in Beijing, Atmos. Environ., 39, 3771-3784, 2005a.

Wang, Y., Hu, B., and Liu, G.: A primary study of the variations of vertical radiation with the Beijing 325-m Meteorological tower, Adv. Atmos. Sci., 22, 401-407, 2005 b.

Wang, Y., Zhuang, G., Sun, Y., and An, Z.: The variation of characteristics and formation mechanisms of aerosols in dust, haze and clear days in Beijing, Atmos. Environ., 40, 6579-6591, 2006.

Wehner, B. and Wiedensohler, A.: Long term measurements of submicrometer urban aerosols: statistical analysis for correlations with meteorological conditions and trace gases, Atmos. Chem. Phys., 3, 867-879, 2003, http://www.atmos-chem-phys.net/3/867/2003/.
Wehner, B., Wiedensohler, A., Tuch, T. M., Wu, Z. J., Hu, M., Slanina, J., and Kiang, C. S.: Variability of the aerosol number size distribution in Beijing, China: New particle formation, dust storms, and high continental background, Geophys. Res. Lett., 31(22), L22108, doi:10.1029/2004GL021596, 2004.

Wong, T. W., Tam, W. S., Yu, T. S., and Wong, A. H.: Associations between daily mortalities from respiratory and cardiovascular diseases and air pollution in Hong Kong, China, Occup. Environ. Med., 59(1), 30-35, 2002.

Woo, K. S., Chen, D. R., Pui, D. Y. H., and McMurry, P. H.: Measurement of Atlanta Aerosol Size Distributions: Observation of ultrafine particle events, Aerosol Sci. Technol., 34, 75-87, 2001.

Wu, Z., Hu, M., Liu, S., Wehner, B., Bauer, S., Wiedensohler, A., Petäjä, T., Dal Maso, M., and Kulmala, M.: New particle formation in the mega-city: Beijing, China, J. Geophys. Res., 112, D09209, doi:10.1029/2006JD007406, 2007.

Wu, Z., Hu, M., Pen, L., Liu, S., Wehner, B., and Wiedensohler, A.: Particle number size distribution in the urban atmosphere in Beijing, China, Atmos. Environ., 41, 7967-7980, doi:10.1016/j.atmosenv.2008.06.022, 2008.

Xia, X., Chen, H., and Zhang, W.: Analysis of the dependence of column-integrated aerosol properties on the long-range transport of air masses in Beijing, Atmos. Environ., 41, 7739-7750, 2007.

Yang, Y. Q., Hou, Q., Zhou, C. H., Liu, H. L., Wang, Y. Q., and Niu, T.: Sand/dust storm processes in Northeast Asia and associated large-scale circulations, Atmos. Chem. Phys., 8, 25-33, 2008, http://www.atmos-chem-phys.net/8/25/2008/.

Yao, X., Lau, A. P. S., Fang, M., Chan, C. K., and Hu, M.: Size distributions and formation of ionic species in atmospheric particulate pollutants in Beijing, China: 1inorganic ions, Atmos. Environ., 37, 2991-3000, 2003.

Yu, J., Guinot, B., Yu, T., Wang, X., and Liu, W.: Seasonal variations of number size distributions and mass concentration of atmospheric particles in Beijing, Adv. Atmos. Sci., 22, 401-407, 2005.

Yue, W., Schneider, A., Stolzel, M., Ruckerl, R., Cyrys, J., Pan, X., Zareba, W., Koenig, W., Wichmann, H. E., and Peters, A.: Ambient source-specific particles are associated with prolonged repolarization and increased levels of inflammation in male coronary artery disease patients, Mutat. Res., 621, 50-60, 2007.

Zhang, M., Zhong, Y., and Cai, X.: A health-based assesment of particulate air pollution in urban areas of Beijing in 2000-2004, Sci. Total Environ., 376, 100-108, 2007.

Zheng, M., Salmon, L. G., Schauer, J. J., Zeng, L. M., Kiang, C. S., Zhang, Y. H., and Cass, G. R.: Seasonal trends in $\mathrm{PM}_{2.5}$ source contributions in Beijing, China, Atmos. Environ., 39, 3967-3976, 2005.

Zhong, J., Guangyu, S., and Huansen, C.: Analysis on Aerosol concentration of Beijing during 1998-2001, Climate and Environmental Research, 8(4), 495-502, 2003. 